\title{
Análise dos potenciais ganhos da implantação de um sistema de geração de energia fotovoltaica no fórum de Jaboatão, PE
}

\begin{abstract}
Após a Revolução Industrial, surge um elevado índice de crescimento no consumo de energia, que provoca a nível mundial, uma maior preocupação com o meio ambiente. Desta forma, promove-se estudos baseados em novas formas de energia, surgindo assim, as energias renováveis, dentre elas a energia fotovoltaica que apresenta como vantagem tratar-se de uma fonte inesgotável, não poluente e gratuita. Este trabalho tem como objetivo avaliar os impactos que se obtém no viés financeiro e ambiental, ao adotar a geração fotovoltaica no Fórum de Jaboatão dos Guararapes, podendo ampliar o uso da Energia Solar Fotovoltaica (PV) em Pernambuco, levando em consideração os interesses daqueles que se beneficiam, com esse tipo de instalação. A metodologia se refere à coleta de dados para análise das condições de se implantar um sistema fotovoltaico no Fórum de Jaboatão dos Guararapes, situado na Rodovia cidade de Jaboatão dos Guararapes/PE. A coleta de dados se deu em um período de 12 meses foram levantadas as faturas de energia elétrica nesse período, as situações favoráveis para instalação do sistema PV, quais as condições técnicas, tais quais tipo do telhado, sombreamento, a irradiância, e o custo benefício dessa forma de instalação. Contou-se ainda com a utilização de um importante software o PVSOL, nos fornecendo melhores resultados. Esse estudo obteve como resultado ser viável a implantação do sistema fotovoltaico no referido prédio, com a análise dos parâmetros de viabilidade econômico-financeiros favoráveis, e com uma contribuição ambiental amigável, sendo relevante na diversificação da matriz energética.
\end{abstract}

Palavras-chave: Energia Solar; Poder Público; Sustentabilidade.

\section{Analysis of the potential gains from the implementation of a photovoltaic energy generation system in the forum of Jaboatão, PE}

\begin{abstract}
After the Industrial Revolution, there is a high rate of growth in energy consumption, which causes worldwide concern for the environment. In this way, studies based on new forms of energy are promoted, thus emerging renewable energies, including photovoltaic energy, which has the advantage of being an inexhaustible, non-polluting and free source, as it comes from solar energy, being able to contribute in an intense and effective way in the diversification of the world energy matrix. This work aims to evaluate the impacts that are obtained in the financial and environmental bias, by adopting photovoltaic generation at the Jaboatão dos Guararapes Forum, being able to expand the use of Photovoltaic Solar Energy (PV) in Pernambuco, taking into account the interests of those who benefit from this type of installation. The methodology refers to a collection of data to analyze the conditions of implementing a photovoltaic system at the Jaboatão dos Guararapes Forum, located on the city of Jaboatão dos Guararapes/PE. Data collection took place over a period of 12 months. Electricity bills were collected during this period, the favorable situations for installing the PV system, which are the technical conditions, such as roof type, shading, irradiance, and cost benefit of this form of installation. We also counted on the use of an important software, PVSOL, providing us with better results. This study resulted in the implementation of the photovoltaic system in that building being viable, with the analysis of favorable financial economic viability parameters, and with a friendly environmental contribution, being relevant in the diversification of the energy matrix.
\end{abstract}

Keywords: Solar energy; Public Power; Sustainability.

Topic: Sistemas de Energia Sustentável

Reviewed anonymously in the process of blind peer.
Received: 05/06/2021

Approved: 26/06/2021
Karlla Adriana Rodrigues Barbosa Campelo do Livramento

Faculdade Estácio do Recife, Brasil

http://lattes.cnpq.br/9243535910645257

karlla.adriana2016@gmail.com

Luiz Filipe Alves Cordeiro (iD

Universidade Federal de Pernambuco, Brasil

http://lattes.cnpq.br/4004156784497834

http://orcid.org/0000-0001-8146-9465

filipecordeiro@gmail.com

Wanderson dos Santos Souza

Universidade Paulista, Brasil

http://lattes.cnpq.br/7951797476705365

Wanderson.santos@itep.br
Waléria Guerreiro Lima

Universidade Federal Rural de Pernambuco, Brasil

http://lattes.cnpq.br/4366295977643638

waguelima@gmail.com
Referencing this:

LIVRAMENTO, K. A. R. B. C.; CORDEIRO, L. F. A.; SOUZA, W. S.; LIMA, W. G.. Análise dos potenciais ganhos da implantação de um sistema de geração de energia fotovoltaica no fórum de Jaboatão, PE. Revista Ibero Americana de Ciências Ambientais, v.12, n.6, p.411-425, 2021. DOI: http://doi.org/10.6008/CBPC2179-6858.2021.006.0035 


\section{INTRODUÇÃO}

A revolução industrial, contribuiu de forma relevante para que a energia assumisse uma importante posição no aspecto econômico das sociedades, evidenciando que o crescimento financeiro e social está diretamente relacionado com demanda energética (SILVA et al., 2017).

Com o avanço no desenvolvimento do setor industrial, somando-se ainda, uma elevada utilização de produtos eletro/eletrônicos, pode-se ver claramente a preocupação de estudiosos de todo o mundo, com as consequências em nosso planeta provenientes das mudanças climáticas, ocorridas devido às práticas humanas (BLANK, 2015).

Surge assim, o conceito de Desenvolvimento Sustentável, sendo aquele em que se atende os interesses da geração atual sem comprometer as gerações futuras. Em período de crise de abastecimento de energia, existe um comprometimento no setor elétrico, devido à recente escassez de água, com consequências visíveis, e outras fragilidades naturais no Brasil (TOLLER, 2015).

Como grandes aliadas nesta luta, contra o aquecimento global e as mudanças climáticas, causadoras de grandes tragédias, temos as fontes renováveis, e dentre elas, a energia solar fotovoltaica, a qual, vem ganhando cada vez mais notoriedade no cenário mundial, ao longo da última década, com uma elevada e constante taxa de crescimento que deverá permanecer devido ao apelo mundial por energias limpas, sendo ela umas das mais eficientes e menos nocivas ao meio ambiente (SILVA, 2015).

Além de que, é uma fonte limpa, ou seja, não poluente, que pode ser facilmente desperdiçada em caso de não se utilizá-la de maneira sustentável e racional (AMARAL, 2016). Diante desse aspecto, levandose ainda em consideração a incidência solar sobre as cidades, trata-se de uma fonte imbatível: com zero custo de insumo incidindo sobre áreas construídas, onde pessoas desenvolvem suas atividades com estudo ou trabalho, podendo ser usada para gerar renda em prol da sociedade (EGGERS, 2016).

O objetivo geral deste trabalho é analisar os possíveis ganhos que se pode obter com a implantação de um sistema de geração de energia fotovoltaica em um prédio do Tribunal de Justiça de Pernambuco. Para isso, os objetivos específicos são: levantar o melhor prédio para a implantação do sistema de geração de energia; Avaliar o melhor sistema a ser implantado; Mensurar os ganhos econômicos e ambientais no prédio escolhido.

\section{REVISÃO TEÓRICA}

\section{Contexto Geral}

As mudanças climáticas têm-se feito presentes nas pautas de diferentes esferas, da formulação de políticas públicas às demandas de movimentos sociais, apesar de controvérsias científicas e dificuldades de comunicação, essas mudanças têm demonstrado a condição de pôr em risco o conjunto crítico-conceitual tradicionalmente mobilizado para descrever como a sociedade se organiza (e as relações sociedadenatureza), demandando novas concepções do agir político (FLEURY et al., 2019).

Existem evidências de que fenômenos extremos, como secas, enchentes, ondas de calor e de frio, 
furações e tempestades, têm atingido diversas partes do planeta e causado perdas econômicas e de vidas em larga escala. Como exemplos, podemos citar a onda de calor na Europa em 2003, os furacões Katrina, Wilma e Rita no Atlântico Norte em 2005 e o inverno extremo da Europa e Ásia em 2006. Pode-se ainda citar no Brasil, o furacão Catarina em março 2004, a seca da Amazônia em 2005 e as secas já observadas no sul do Brasil em 2004, 2005 e 2006. Há, inclusive, impactos tais quais alterações na biodiversidade, elevação no nível do mar e impactos na saúde, na agricultura e na geração de energia hidrelétrica, que já podem estar afetando o Brasil, assim como o restante do planeta, a Europa em 2003, teve seu verão considerado o mais quente dos últimos 500 anos matando entre 12 mil e 15 mil pessoas (BLANK, 2015).

A China é o maior emissor de GEE no mundo, $29 \%$ das emissões globais são oriundas da China, esse país em 2007, ultrapassou as emissões dos Estados Unidos. Entre as décadas de 1990 a 2010, teve um crescimento de mais de $300 \%$, resultante das profundas alterações sociais, promovidas a partir do Plano das Quatro Modernizações de 1978, responsável por inserir a china no contexto econômico global (BARBIERI et al., 2015). As altas emissões são diretamente associadas à queima de combustíveis fósseis, principalmente do carvão, principal matriz energética da China correspondendo a um percentual de mais de $60 \%$ da produção energética anual (LIU, 2015).

\section{Política Ambiental}

É evidente que o fato de investir em desenvolvimento e aderir a novas tecnologias contribui para o setor de energia tornar-se sustentável, mas além destas ações se faz necessário implantar mudanças que abranjam uma política ambiental, ou seja, uma maior consciência por parte da população em atitudes sustentáveis e um maior empenho no assunto por parte das autoridades, desta forma estudos apontam que existe uma relação entre consciência ambiental e o comportamento pró ambiental da sociedade, estando atrelado principalmente à disseminação de notícias referente a desgastes ambientais e de que o consumo de energia deve ser sustentável, que possa refletir as consequências do comportamento da sociedade, desenvolvido através de educação ambiental (SOUZA, 2017).

No aspecto energético tem-se desde a década de 80 a criação de dois importantes programas, são eles, o Programa de Conservação de Energia Elétrica (PROCEL), criado em 1985 pelo Governo Federal e que segundo a ELETROBRAS, órgão que executa tal programa, "Promove o uso eficiente da energia elétrica, ajudando a combater o desperdício e a reduzir os custos e os investimentos setoriais", e o Programa Nacional de Racionalização do uso dos derivados de petróleo e gás natural (COMPET), o qual possui, como empresa coordenadora, a Petrobras (LOPES et al., 2016).

Na década de 90, o Brasil avançou de forma relevante com essa política, no sentido que foram aprovadas diversas leis setoriais, como a Lei Nacional de Recursos Hídricos (1997) já no ano seguinte a de crimes ambientais e a da Política Nacional de Educação Ambiental no ano de 1999 (BRASIL, 1997; 1999).

Segundo o Ministério de Minas e Energia o MME, por meio do Comitê Gestor de Eficiência Energética (CGEE), em sua 14a reunião, a qual realizou-se no dia 07/07/2020, foi aprovado o Terceiro Plano de Aplicação de Recursos do Programa Nacional de Conservação de Energia Elétrica - PAR Procel 2020/2021, 
caracterizando-se um avanço no quesito sustentabilidade do setor energético.

\section{Energia Solar Fotovoltaica}

As primeiras descobertas quanto ao tema abordado ocorreram em meados de 1839 , quando o físico e cientista francês, Beqquerel, através de experimentos verificou uma tensão elétrica que resultou da ação da luz sobre um eletrodo metálico mergulhado em uma solução química, posteriormente em 1877, Adams e Day, cientistas ingleses, observaram um efeito parecido no selênio, outro tipo de semicondutor (RABUSKE et al., 2018).

O conceito de energia solar fotovoltaica se define como sendo a energia obtida através da conversão direta da luz em eletricidade, tendo como unidade fundamental desse processo de conversão a célula fotovoltaica, um dispositivo fabricado com um material semicondutor. Existem três gerações das principais tecnologias aplicadas na produção de células e módulos fotovoltaicos, onde a 1a geração é dividida em duas cadeias produtivas : silício monocristalino (m-Si) e silício ploicristalino ( $p-\mathrm{Si})$, representando mais de $85 \%$ do mercado por ser de uma tecnologia consolidada e confiável e possuir uma maior eficiência, a 2a geração denominada filmes finos, dividida em três cadeias produtivas: silício amorfo (a-Si), disseleneto de cobre e índio (CIS) ou disseleneto de cobre, índio e gálio (CIGS) e telureto de cádmio (CdTe), essa geração apresenta menor eficiência que a primeira e modesta participação no mercado e a 3a geração ainda em fase de Pesquisa e Desenvolvimento (P\&D), testes e produção é dividida em três cadeias produtivas: célula fotovoltaica multijunção e célula fotovoltaica para concentração, células sensibilizadas por corante e células orgânicas ou poliméricas (EPE, 2014).

Para Silva et al. (2019), para a produção de energia elétrica são utilizados painéis fotovoltaicos, formados por grupos de células fotovoltaicas eletricamente interligadas, somando-se as tensões geradas por cada uma delas. O silício, o qual se trata de um dos materiais mais utilizados na construção de células solares, necessariamente deve conter um alto grau de pureza, sendo necessários sofisticados processos de refino. Atualmente os três tipos de tecnologias aplicados na produção dessas células são empregados na construção de painéis fotovoltaicos: o silício monocristalino, o silício policristalino e o silício amorfo de filme fino. Essas tecnologias apresentam diferenças entre si no que diz respeito à sua eficiência, resultando em células que produzem quantidades diferentes de energia a partir de uma mesma quantidade de luz solar recebida.

Segundo Cengiz et al. (2015), os painéis fabricados utilizando-se o silício cristalino apresentam $20 \%$ de eficiência, em contrapartida os painéis construídos a partir da tecnologia do silício amorfo apresentam 10\% de eficiência, as células fotovoltaicas fabricadas à base de silício mono ou policristalino perfazem o percentual entre $85 \%$ e $90 \%$ do mercado de painéis solares.

A luz tem sua descrição baseada em qualquer uma das seguintes propriedades físicas: frequência (f), comprimento de onda $(\lambda)$, ou por ondas eletromagnéticas (energia) (E).

Seu cálculo se dá através da Equação 1, sendo " $h$ " a constante de Plank (6,626 × 10-34 $\left.\mathrm{m}^{2} \mathrm{~kg} / \mathrm{s}\right)$ e "c" a velocidade da luz no vácuo em m/s (MEYER et al., 2019). 


$$
E=\frac{h c}{\lambda}
$$

Esta energia incidente, somente pode ser aproveitada, na presença de um campo elétrico. Desta forma, utiliza-se a camada de depleção que surge ao unirem-se dois cristais semicondutores, um dopado positivamente e outro negativamente. Fabricam-se Células fotovoltaicas com material semicondutor, normalmente o silício, por possuir baixa condutibilidade. Por exemplo: Da dopagem do silício com o fósforo obtém-se um material portador de carga negativa (silício tipo $\mathrm{N}$ ) e com boro obtém-se um material com cargas positivas livres (silício tipo P). Cada célula solar é composta de camada fina de material tipo $\mathrm{N}$ e outra com maior espessura de material tipo P, como mostra a Figura 1 (EPE, 2014).
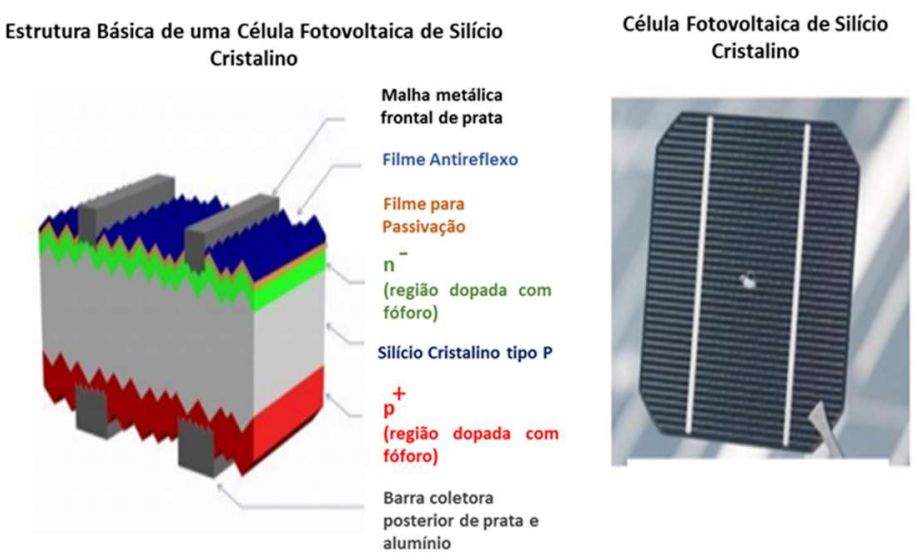

Figura 1: Estrutura de uma célula solar. Fonte: Adaptado de EPE (2014).

Para que ocorra uma produção significativa de energia, uns certos números de células são associados para formação de módulos, por sua vez os painéis são formados a partir da junção de módulos, a qual define os geradores fotovoltaicos (Figura 2).
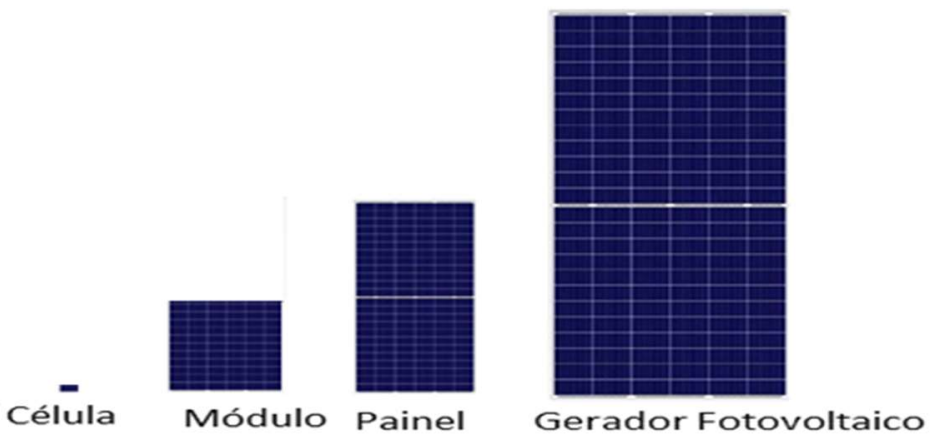

Figura 2: Esquema básico de um gerador fotovoltaico.

\section{Legislação}

A Agência Nacional de Energia Elétrica, no ano de 2011 em parceria com empresas concessionárias de energia elétrica no Brasil apresentou o projeto Arranjos Técnicos e Comerciais com o objetivo de inclusão de Geração Solar Fotovoltaica na Matriz Energética Brasileira que em conjunto com a publicação da resolução no 482 representou um marco para a inserção da energia fotovoltaica no país, baseando-se na interligação de usinas experimentais de energia fotovoltaicas ao sistema elétrico nacional, atingindo quase $25 \mathrm{MW}$ de 
capacidade instalada de geração (BELLELIS, 2019).

Desde 17 de abril de 2012, quando entrou em vigor a Resolução Normativa ANEEL no 482/2012, o consumidor brasileiro pode gerar sua própria energia elétrica a partir de fontes renováveis ou cogeração qualificada e inclusive fornecer o excedente para a rede de distribuição de sua localidade. Trata-se do micro e da minigeração distribuídas de energia elétrica, sendo criado o sistema de Compensação de Energia, o qual permite que fontes de até $1 \mathrm{MW}$ de potência possam se conectar, para consumo local à rede elétrica, (GEHRING et al., 2015) inovações que podem aliar economia financeira, consciência socioambiental e autossutentabilidade.

A energia produzida que não foi utilizada é injetada na rede da concessionária para que possa ser utilizada em períodos em que o sol não está presente - noites e momentos de clima muito nublado, ou nevascas - permitindo que a eletricidade seja fornecida sem interrupções. Os sistemas fotovoltaicos conectados à rede constituem-se basicamente do painel fotovoltaico e do inversor, sendo assim não se utiliza elementos para armazenar a energia elétrica, ficando a função de armazenamento a encargo da própria rede elétrica (SOUZA, 2016). Essencialmente, toda a energia gerada é entregue instantaneamente à rede pública. Desta forma, quando não há sol e quando não há irradiação solar, o consumidor utiliza a eletricidade que vem diretamente da rede elétrica (RABUSKE et al., 2018).

A ANEEL em 30 de dezembro de 2014 publicou a Nota Técnica no 086/2014-SRG-SRD/ANEEL com a finalidade de apresentar um resumo das contribuições e os comentários das áreas técnicas da ANEEL que se referem à Consulta Pública no 005/2014, a qual deu início à discussão junto à sociedade a respeito da necessidade de criação de incentivos para a instalação de centrais geradoras com potência instalada superior a $1 \mathrm{MW}$ pertencentes a consumidores bem como a ampliação dos limites de aplicação do conceito de Net Metering para essas centrais, além de obter informações adicionais sobre o tema.

Todas as concessionárias de energia devem estar prontas para receber, analisar e viabilizar a conexão de GD nas suas áreas de concessão, devendo o setor de planejamento se encarregar de incluir, em casos cabíveis, estudos de melhores condições à expansão do sistema elétrico local, por meio de análise de conexão de geração externa (AMARAL, 2016).

\section{Fatores para análise da viabilidade econômico financeira do projeto}

\section{Taxa Mínima de Atratividade (TMA)}

Alves et al. (2019), afirma que a "TMA - Taxa Mínima de Atratividade é o retorno líquido obtido pela aplicação do capital de investimento em títulos de baixo risco e compatíveis com o perfil do investidor".

\section{Valor Presente Líquido (VPL)}

VPL pode-se conceituar como o desconto do valor dos fluxos futuros, aplicando-se uma determinada taxa de juros, de maneira que este fluxo futuro se apresente a valores atuais. 
Taxa Interna de Retorno (TIR)

Para Zulpo et al. (2020), a taxa interna de retorno define qual empreendimento possui uma maior viabilidade, tendo em vista reportar-se ao investimento que gera maior rentabilidade, considerando-se uma taxa pré-definida pelo empreendedor.

\section{Payback descontado}

Pretende-se demonstrar em qual momento temporal as receitas alcançarão o somatório dos investimentos realizados pelo negócio, de acordo com as expectativas de fluxo de caixa.

\section{METODOLOGIA}

\section{Estrutura}

Inicialmente foi feito um estudo de viabilidade de melhor custo-benefício dos prédios do Judiciário para implantação do sistema solar, com vários estudos de viabilidade frente aos tomadores de decisão, e ao Corpo Técnico de Engenheiros/TJPE sendo observado que a estrutura do Fórum Rodolfo Aureliano não suportaria o peso das placas, possuindo ainda uma grande área vazada o que inviabilizaria a instalação das placas, ainda foi avaliado um segundo prédio, este localizado no município de Custódia situado no sertão do Estado de Pernambuco, pois possui uma grande área no exterior do prédio, mas ocorreria perda no rendimento, devido ao fato da grande incidência solar, o que levaria a uma maior probabilidade de as placas se sujarem e ainda se perderia área verde do prédio, também inviabilizando o estudo desta forma entendeuse ser o prédio que abriga o Fórum de Jaboatão dos Guararapes, o mais viável para a administração do TJPE, o qual possui uma subestação que alimenta dois prédios (cada um com $12.000 \mathrm{~m}^{2}$ de área, podendo ser as placas instaladas em ambas as cobertas.

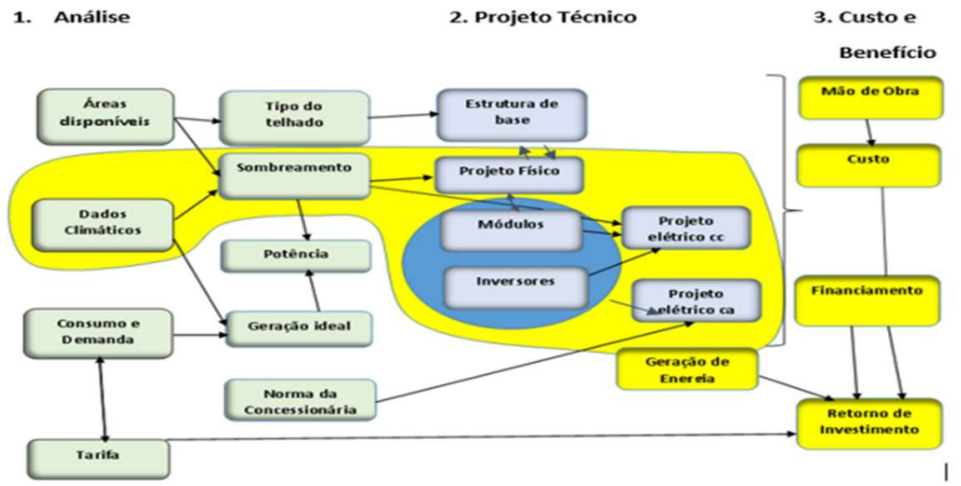

Figura 3: Etapas de um projeto de um sistema de energia solar ligado à rede.

Após a análise do prédio, continuou-se a pesquisa que, trata-se de uma metodologia quantitativa, no momento que baseia-se principalmente em demonstrar por meio de análise das dados estatísticos, através de visitas de empresas especializadas na implantação do sistema solar fotovoltaico, de forma a colher dados necessários para se elaborar uma planilha orçamentária dos custos de investimento, inclusive efetuar cálculos que justifiquem a implantação do sistema, com período de retorno do investimento. 
A Figura 3, apresenta um fluxograma demonstrando as etapas envolvidas em uma elaboração de um projeto de sistema de energia solar ligado à Rede. Observe que a geração ideal, não considera o sombreamento, motivo que nos impede de alcançarmos uma geração ideal.

\section{Estudo de caso}

O presente estudo refere-se a uma coleta de dados para análise das condições de se implantar um sistema fotovoltaico no Fórum de Jaboatão dos Guararapes, uma edificação de 6 pavimentos com uma área construída de $12.000 \mathrm{~m}^{2}$, situado na Rodovia BR 101, PE.

Seguem as etapas consideradas na referente Pesquisa: 1) Obtenção junto à Diretoria de Engenharia e Arquitetura - DEA/TJPE, dos projetos arquitetônicos dos diversos pavimentos do Fórum de Jaboatão dos Guararapes; 2) Coleta das faturas de energia elétrica em um período de 12 meses que no nosso caso, variou de fevereiro de 2019 a fevereiro de 2020, faturas coletadas através do setor responsável do Tribunal de Justiça de Pernambuco - DIRIEST; 3) Por meio da ferramenta excel, foi elaborada uma planilha contemplando os valores de consumo, demanda e o valor em $\mathrm{R} \$$ de cada fatura mensal, com o valor médio, conforme indica o Quadro 1; 4) Envio dos projetos/faturas de energia para empresas de Instalação de Energia Fotovoltaica; 5) Estudo/utilização do software PVSOL, utilizado para dimensionamento do sistema abordado.

O dimensionamento do sistema fotovoltaico do Fórum de Jaboatão dos Guararapes - Tribunal de Justiça de Pernambuco - foi obtido por meio do software PVSOL Premium, um software de design e simulação para sistemas fotovoltaicos, o PVSOL, o qual se trata de um programa de simulação dinâmica com visualização 3D e análise detalhada. Segue, uma explicação dos passos a serem considerados, para a definição do sistema fotovoltaico. 1) Na aba base de dados, tem-se a opção de se escolher o tipo de sistema fotovoltaico, que para nosso estudo, foi utilizado o sistema fotovoltaico conectados à rede com consumidores elétricos, temos ainda que preencher a aba dos dados climáticos, que são automáticos no momento em que definimos a localidade da pesquisa e informar a tensão fase, o fator de potência, a quantidade de fases do sistema elétrico. Cumprida essa etapa, prossegue-se para a próxima. 2) Na tela de Consumo, deve-se anotar o consumo mês a mês obtidos por meio das faturas de energia elétrica CELPE. De imediato o software já indica o consumo por meio de um gráfico, conforme a figura x. 3) A etapa 3, consiste na definição dos módulos fotovoltaicos, inclusive a situação de montagem como o tipo do telhado, a inclinação e a orientação dos painéis. 4) Próxima etapa, o dimensionamento do inversor, o qual o software escolhe com base na seleção já definida anteriormente. Em seguida ocorre a definição das perdas, que um valor adequado conforme indica a empresa Solarize, gira em torno de 1\%.5) Após realizados os passos acima descritos, parte-se para a análise financeira, com a tela inicial definida como Parâmetros Financeiros, referindo-se a próxima tela, aos Parâmetros gerais, ocasião em que se define o prazo da instalação, após isso uma segunda tela surge com custos e subsídios, momento em que se define o custo do sistema por KWp, custos operacionais, bem como a taxa de inflação. Ainda em análise financeira parte-se agora para o conceito de injeção, define-se neet metering, onde se faz necessário definir essa nova tarifa, e o software busca pela localidade e particularidades da própria concessionária de energia local, e finalmente chega-se aos 
resultados. Na análise da etapa 3, da nossa Pesquisa, utilizou-se a Equação (2).

$$
\text { Energia }_{\text {Geração }}=\text { Potência Total } \text { Painéis } x \text { Tempo }_{\text {Exposição }} x \eta_{\text {Rendimento }}
$$

$$
\text { Potência } \text { Total }_{\text {Painéis }}=\frac{\text { Energia }_{\text {Geração }}}{\text { Tempo Exposição } \times \eta_{\text {Rendimento }}} \quad \text { (Eq. 2) }
$$

$$
\text { Energia }_{\text {Geração }}=\frac{\text { Média }_{\text {consumo }(k w h)}}{30}
$$

$$
\begin{aligned}
\text { Tempo }_{\text {Exposição }}=H S P & =\left(\frac{k w h}{m^{2} \cdot d i a}\right) \\
\eta_{\text {Rendimento }} & =\text { Perdas }
\end{aligned}
$$

Com o valor do consumo médio mensal, obtido por meio das faturas de energia elétrica, considerando-se ainda, o tipo de ligação, que no estudo presente deverá ser trifásica, o que pela concessionária o consumidor tem que pagar pelo menos $100 \mathrm{KWh} / \mathrm{mês}$ para a Concessionária, encontra-se a energia de geração em KWh/mês, que para ser aplicada na Equação (1), se faz necessário dividir esse valor por 30 dias. Através do site do CRESESB, com a latitude e longitude do local, deve-se utilizar o valor médio no plano horizontal, para obter-se o tempo de exposição em HSP (horas sol pico) que será em $\mathrm{kwm}^{2} / \mathrm{dia} \mathrm{e}$ por fim o rendimento que considera os fatores tais quais Perdas por Temperatura, Incompatibilidade Elétrica, Acúmulo de Sujeira, Cabeamento CC, Cabeamento CA e inversores, parâmetros com faixa de valores previamente definidos. Ao realizar a substituição dessas variáveis na fórmula é obtida a energia necessária em Kwp.

Ao utilizar-se o software PVSOL, encontra-se o valor da energia injetada na rede anualmente, a qual deve ser multiplicada pela tarifa de injeção específica coletada junto à Concessionária de Energia $\left(T_{b c i}\right)$ conforme Quadro2, o que acarretará no valor da Geração Anual $\left(G_{\text {Anual }}\right)$.

Ocorre que para se obter a Energia Anual Corrigida, Quando 3, deve-se considerar fatores tais quais degradação, aumento de energia e porcentagem de energia utilizada, que se obtém através do software em questão, os quais verifica-se no Quadro 2.

$$
E_{A C}=G_{\text {Anual } x} T_{b c i}\left(1+A_{\text {Energia }}\right)^{(\text {Ano-1) }} x\left(P_{A C} \times \phi_{\text {Módulo }}\right)
$$

Onde, do Quadro 2, tem-se:

$G_{\text {Anual }}=$ Geração Anual

$A_{\text {Energia }}=$ Aumento $_{\text {Energia }}$

$P_{A C}=$ Porcentagem de Autoconsumo

$\phi_{\text {Módulo }}=$ Rendimento do Módulo

Ainda se faz necessário, obter-se o valor referente ao Valor Presente, o qual se dá através da Equação

3, onde tem-se que o fluxo de caixa será igual ao valor da energia anula corrigida.

$$
V_{P=\sum_{j=1}^{n}} \frac{F C_{j}}{(1+T M A)^{j}}
$$

\section{RESULTADOS}

O presente trabalho, apresenta simulações em três dimensões, por meio de uma análise minuciosa 
dos parâmetros principais envolvidos na definição do sistema de energia solar, demonstrando 06 áreas desenhadas, calculando e verificando as condições de instalação dos painéis solares, através de um programa de vários módulos de visualização e uma série de displays com informações técnicas sobre como o sistema está reagindo a cada maneira de instalação testada. A Figura 4, relata a imagem panorâmica, modelagem 3d do Fórum de Jaboatão dos Guararapes.

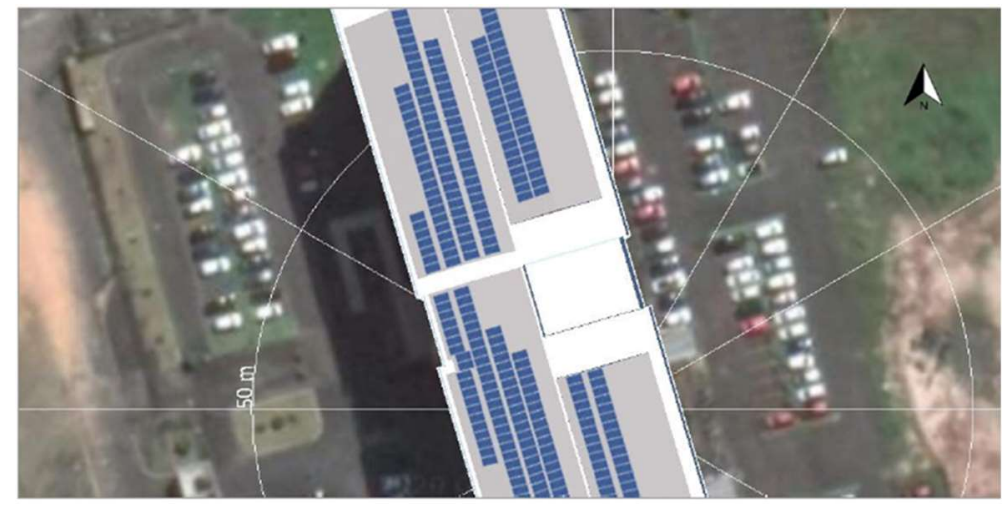

Figura 4: Vista Panorâmica 3D.

O que proporcionou o dimensionamento de um sistema fotovoltaico, com 02 configurações, onde uma das configurações abrange 06 áreas desenhadas e a outra abrange 02 áreas desenhadas, por fim o sistema recebe 02 inversores. 0 Quadro 2 estabelece os dados técnicos do sistema fotovoltaico, encontrados pelo Pvsol.

O Quadro 1, relata o resumo das faturas de energia elétrica, com base no consumo e demanda de energia do Fórum de Jaboatão dos Guararapes.

Quadro 1: Consumo/Demanda de Energia.

\begin{tabular}{|c|c|c|c|c|c|}
\hline \multirow[b]{2}{*}{$\begin{array}{l}\text { Resumo F. Jaboatão } \\
\text { (kwh) }\end{array}$} & \multicolumn{2}{|l|}{ Leitura mensal } & \multicolumn{2}{|l|}{ Demanda } & \multirow{2}{*}{$\begin{array}{l}\text { Fatura } \\
\text { Valor }(R \$)\end{array}$} \\
\hline & $\begin{array}{l}\text { Consumo Ativo na Ponta } \\
\text { (kwh) }\end{array}$ & \begin{tabular}{l}
\multicolumn{2}{l}{ Consumo } \\
Fora de Ponta \\
$(\mathrm{kwh})$
\end{tabular} & $\begin{array}{l}\text { Ativa na Ponta } \\
\text { (kw) }\end{array}$ & $\begin{array}{l}\text { Ativa ultrapassagem } \\
(\mathrm{kw})\end{array}$ & \\
\hline FEV/19 & $5.989,34$ & $91.252,00$ & 505,68 & 25,68 & $52.549,55$ \\
\hline MAR/19 & $5.821,34$ & $98.868,00$ & 541,52 & 61,52 & $51.506,59$ \\
\hline ABR/19 & $6.832,84$ & $115.416,00$ & 577,36 & 97,36 & $49.956,99$ \\
\hline $\mathrm{MAl} / 19$ & $5.639,76$ & $99.834,00$ & 558,88 & 78,88 & $52.179,54$ \\
\hline JUN/19 & $6.058,38$ & $99.288,00$ & 480,00 & 0,00 & $47.666,62$ \\
\hline JUL/19 & $5.943,42$ & $92.932,00$ & 483,28 & 0,00 & $44.549,28$ \\
\hline AGO/19 & $5.607,00$ & $82.208,00$ & 480,00 & 0,00 & $42.462,82$ \\
\hline SET/19 & $5.341,56$ & $82.040,00$ & 480,00 & 0,00 & $43.881,92$ \\
\hline OUT/19 & $5.354,16$ & $81,074,00$ & 480,00 & 0,00 & $44.704,73$ \\
\hline NOV/19 & $5.882,94$ & $96.012,00$ & 480,00 & 0,00 & $50.619,38$ \\
\hline DEZ/19 & $5.550,16$ & $98.700,00$ & 480,00 & 0,00 & $50.486,78$ \\
\hline JAN/20 & $6.217,54$ & $103.782,00$ & 530,00 & 50,00 & $51.808,02$ \\
\hline FEV/20 & $4.758,04$ & $77.476,00$ & 530,00 & 50,00 & $41.213,02$ \\
\hline MÉDIA & $5.768,96$ & $93.760,15$ & 508,21 & 27,96 & $47.968,10$ \\
\hline
\end{tabular}

Após estudos sistemáticos, frente aos dados coletados, foi sugerido um gerador fotovoltaico com potência de 96,40 KWp, o que parece ser uma potência não tão atraente, diante da sugestão de algumas empresas especializadas em energia fotovoltaica, onde por meio de uma análise mais breve, sugeriu-se que fossem adotados geradores fotovoltaicos com potência de 686,75 KWp; 776,00 KWp e 777,15 KWp.Que 
foram determinadas, através da Equação (1), com variação no índice do rendimento (Quadro 2).

Quadro 2: Dados de Entrada.

\begin{tabular}{|c|c|c|}
\hline \multicolumn{3}{|c|}{ INFORMAÇÕES TÉCNICAS } \\
\hline Nome do Cliente & \multicolumn{2}{|c|}{ Tribunal de Justiça do Estado de PE - Jabotão dos Guararapes } \\
\hline Potência da usina & & $96,4 \mathrm{kWp}$ \\
\hline Investimento em equipamentos & $\mathrm{RS}$ & $402.291,84$ \\
\hline Investimento inicial & $\mathrm{R} \$$ & $402.291,84$ \\
\hline Cidade & & Jaboatao dos Guararapes \\
\hline Irradiação média mensal & & $96 \mathrm{kWp}$ \\
\hline PR (Perfomance Ratio) & & 0,787 \\
\hline Geração média mensal & & $12.594,33 \mathrm{kWh}$ \\
\hline Geração anual & & $151.132,00 \mathrm{kWh}$ \\
\hline ICMS & & $0,00 \%$ \\
\hline PIS & & $0,90 \%$ \\
\hline CONFINS & & $4,15 \%$ \\
\hline Grupo tarifário & & Grupo A \\
\hline Estado Conveniado a Convenio ICMS & & Sim \\
\hline Tarifa básica sem Impostos & $\mathrm{RS}$ & - \\
\hline Bandeira Tarifária & & Vermelha \\
\hline Tarifa básica com impostos & $\mathrm{RS}$ & 0,3219 \\
\hline Aumento da energia & & $8,92 \%$ \\
\hline Inflação & & $3,00 \%$ \\
\hline Porcentagem de Autoconsumo & & $100,00 \%$ \\
\hline Tempo de Análise & & 25 anos \\
\hline
\end{tabular}

Desta forma, como já dito na metodologia aplicada, esse grande decréscimo ocorreu por motivo das áreas de sombreamento, existentes em diferentes locais do telhado da construção ora estudada. Ainda assim, projeta-se injetar anualmente na rede, já no primeiro ano, a energia de $151.132 \mathrm{KWh}$, de acordo com o Quadro 2.

Conforme mencionado na metodologia, ao multiplicar-se a energia de $151.132 \mathrm{KWh}$ pela tarifa da Concessionária R\$ 0,3219, encontra-se a Geração Anual no valor de $\mathrm{R} \$$ 48.649,39 (Quarenta e oito mil, seiscentos e quarenta e nove reais e trinta e nove centavos), que ao ser aplicada, na Equação 2, juntamente com alguns parâmetros do Quadro 2, Também já mencionados na metodologia, tem-se a Energia Anual

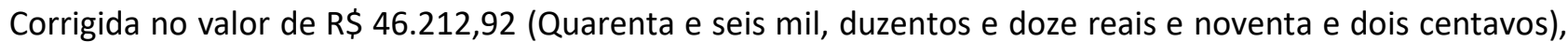
conforme Quadro 3.

Que ao aplicar-se a Equação 3 obtém-se o Valor Presente na quantia de $\mathrm{R} \$$ 44.870,80 (Quarenta e quatro mil, oitocentos e setenta reais), subtraindo-se o valor presente encontrado do valor do investimento inicial, teremos o valor acumulado que no nosso caso, considerando o primeiro ano, totaliza a quantia de R\$ $-357.421,04$, e assim continuamos aplicando essas equações a cada ano.

Do Quadro 03, tem-se que a taxa interna de retorno apresentou o valor de $15,53 \%$, o payback o valor de 7 anos (período em que se dará início ao retorno do investimento), do Quadro 4, percebe-se uma redução na emissão de $\mathrm{CO}^{2}$ anual da ordem de $90.679 \mathrm{Kg} / \mathrm{ano}$, do Quadro 5, verifica-se ainda que com um investimento inicial de $\mathrm{R} \$ 402.291,84$, o Tribunal de Justiça de Pernambuco ao longo de 25 anos (período de garantia do sistema), terá o valor Presente Líquido de $\mathrm{R} \$ 2.358 .416,60$. 
Quadro 3: Análise Anual - Visão do Consumidor.

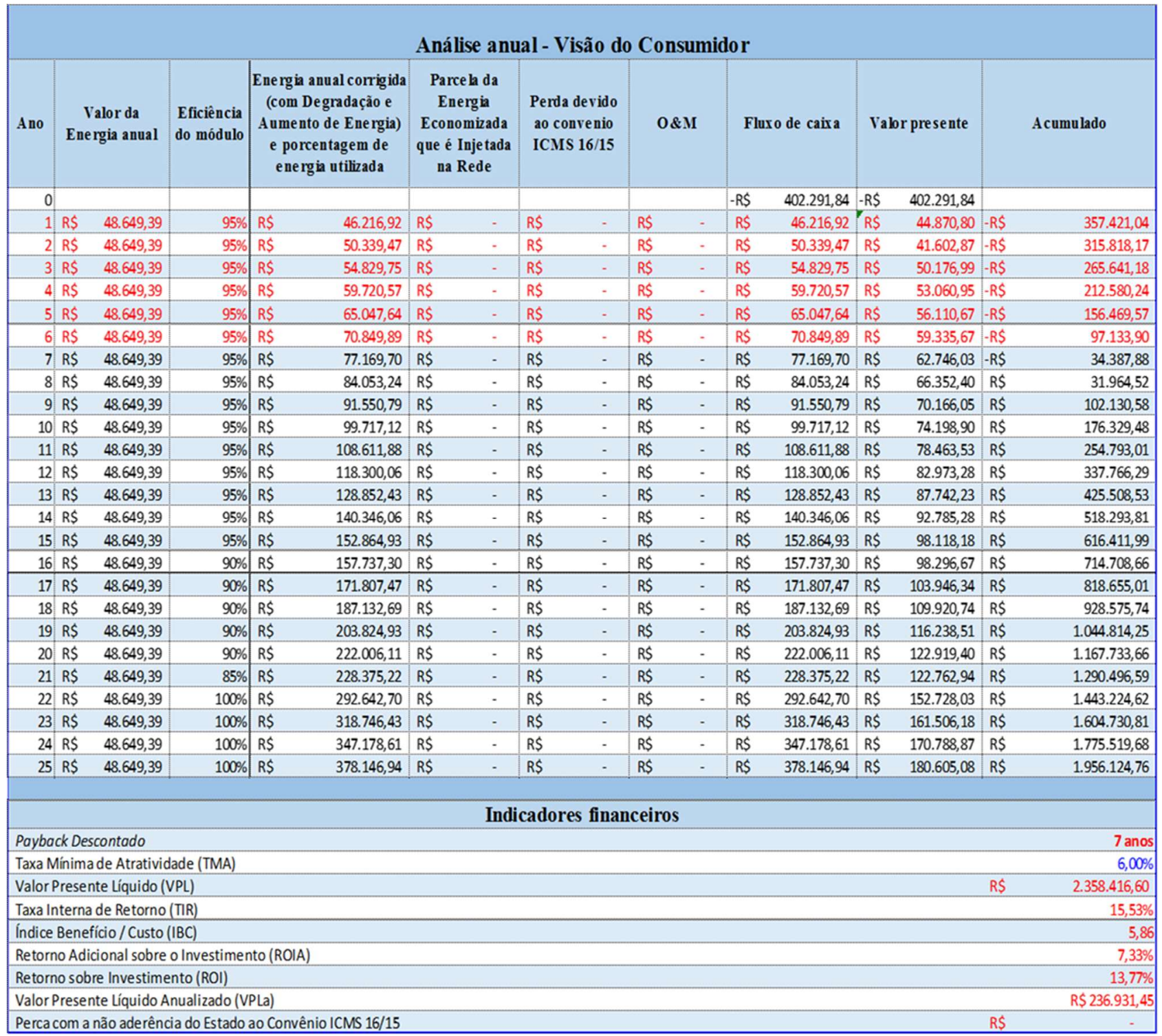

Quadro 4: Sistema fotovoltaico.

SISTEMA FOTOVOLTAICO

Potência do gerador fotovoltaico

Rendimento anual específico

96,4 KWp

$1568,41 \mathrm{KWh} / \mathrm{KWp}$

$78,70 \%$

Diminuição do rendimento por sombreamento

$5,6 \% /$ ano

Injeção na rede

Injeção na rede no primeiro ano (incluindo a degradação por módulo)

151.132 KWh/ano

$150.462 \mathrm{KWh} / \mathrm{ano}$

$4 \mathrm{KWh} / \mathrm{ano}$

$90.679 \mathrm{Kg} /$ ano

Emissões de $\mathrm{CO} 2$ evitadas

Quadro 5: Parâmetros Econômicos.

\section{RESUMO FINANCEIRO}

Taxa interna de retorno

Pay Back (Prazo de retorno do investimento)

4.190,54 R\$/KWp

Investimento específico

402.291,84 R\$

Remuneração total no primeiro ano

48.649,39 R\$/ano

Tarifa de injeção específica

$0,3219 \mathrm{R} \$ / \mathrm{KWh}$

Valor Presente Líquido (VPL) - 25 anos

2.358.416,60RS 
A partir da relação benefício/custo e calculando-se um valor positivo de TIR, verifica-se a viabilidade do estudo economicamente na implantação, operação e manutenção do sistema ao final de 20 anos, uma vez que a TIR, apresenta-se muito atrativa em relação à taxa mínima de atratividade empregada (ROSA et al., 2016).

Ainda, para Rosa et al. (2016), os estudos levantados no projeto apresentaram como a relação benefício/custo o valor de 4,46 e a TIR em 22,25\% superior ao CDB. A análise da Taxa Interna de Retorno (TIR) foi dada através da comparação com a Taxa Mínima de Atratividade (TMA). Nesse projeto levou-se em consideração como TMA o valor de um investimento em um certificado de depósito bancário (CDB) para pessoa jurídica não financeira acumulado dos últimos 12 meses, ou seja, de julho de 2014 a junho de 2015, que segundo o Banco Central do Brasil foi de 7,15\%. Concluindo-se, que, caso o estudo apresente uma TIR maior do que o $\mathrm{CDB}$, é considerado viável economicamente. Ambos os resultados evidenciam a viabilidade econômica deste estudo. Ainda, o tempo de retorno demostra que este estudo é um excelente investimento sendo que a partir do $5^{\circ}$ ano passa a apresentar um VPL muito atrativo.

Por meio do estudo realizado em Vier et al. (2017), concluiu-se que para habitações de interesse social, utilizar sistema de placas fotovoltaicas para geração de energia de forma individual, torna-se inviável. Segundo dados obtidos, o tempo de retorno do investimento seria de 15 anos, porém o tempo de retorno adequado seria em média 6 anos. Sendo assim, para sequência do estudo, deverá existir a análise da viabilidade de implementação de uma usina que gere energia elétrica de forma conjunta, para todas as habitações do loteamento e não individual como fora avaliado nesse trabalho.

Além da economia no aspecto financeiro, que se obtém com a geração de energia solar, a adoção do sistema fotovoltaico apresenta ainda como vantagens a geração de energia renovável, sem emissão de ruídos e sem emissão de gases poluentes. Esses indicativos, contribuem para redução do impacto ambiental.

\section{CONCLUSÕES}

No presente estudo, analisando-se a metodologia, ficou evidenciada a escolha do prédio destinado ao Fórum de Jaboatão dos Guararapes, tendo em vista sua vantajosa área de construção, oferecendo a possibilidade de instalar-se as placas no telhado do referido empreendimento, sem comprometer sua estrutura e sem causar perda no rendimento por excessiva sujeira acumulada nas placas.

Diante das possíveis formas de se implantar um sistema fotovoltaico, também foi analisado o risco que uma empresa corre ao solicitar orçamentos sem uma conferência mais detalhada, como ocorreu no nosso estudo, a utilização de um software específico para energia fotovoltaica, pois os valores de geração solar, inicialmente sugeridos não atenderia na prática a nossa necessidade, o que provavelmente provocaria problemas futuros em relação aos valores orçados, podendo causar problemas de ordem econômico financeira, com comprometimento do erário público, uma vez que se teria, no mínimo perda de tempo e trabalho, caso a sugestão das empresas quanto ao Gerador Fotovoltaico proposto fosse considerado como um valor base em uma planilha licitatória.

Neste estudo, obteve-se a Taxa Interna de Retorno de 15,53\%, o indicador índice benefício/custo 
(IBC), apresentou o valor de 5,86, alcançou-se ainda um VPL de R\$2.358.416,60, com um payback de 07 anos, com uma redução de quase 100 toneladas de $\mathrm{CO} 2$, por ano, sendo constatado os benefícios da instalação de um sistema solar fotovoltaico no fórum de Jaboatão dos Guararapes nos vieses econômicos e ambientais.

\section{REFERÊNCIAS}

ALVES, S.; PEDRO, J. J.; SENFF, C. O.; RODRIGUES, R. D. S. A.; WITT, C.. Custos de produção, expectativas de retorno e de risco associados ao plantio de tabaco no município de Rio Negro Paraná/Brasil. In: CONGRESSO BRASILEIRO DE CUSTOS-ABC, 26. Anais. 2019.

AMARAL, R. C.. Impacto técnico e econômico da energia solar fotovoltaica em prédios públicos através de geração distribuída. Dissertação (Mestrado em Engenharia Elétrica) Universidade Federal de Santa Maria, Santa Maria, 2016.

ANEEL. Resolução Normativa ANEEL n. 482, de 17 de abril de 2012. ANEEL, 2012.

BARBIERI, M. D.; FERREIRA, L. C.; BARBI, F.. Governando as mudanças climáticas. Ideias, v.9, n.2, p.71-98, 2018.

BELLELIS, A. A.; MELO, D. C. P.. Uso da energia solar no semiárido pernambucano. Educação Ambiental em Ação, 2019.

BLANK, D. M. P.. O contexto das mudanças climáticas e as suas vítimas. Mercator, Fortaleza, v.14, n.2, p.157-172, 2015.

BRASIL. Lei 9.795, de 27 de abril de 1999. Dispõe sobre a educação ambiental, institui a Política Nacional de Educação Ambiental e dá outras providências. Brasília: DOU, 1999.

BRASIL. Lei 9.433, de 08 de janeiro de 1997. Institui a política Nacional de Recursos Hídricos. Brasília: DOU, 1997.

CENGIZ, M. S.; MAMIS, M. S.. Price-efficiency relationship for photovoltaic systems on a global basis. International Journal of Photoenergy, Cairo, p.1-2, 2015. DOI: https://doi.org/10.1155/2015/256101

ROSA, A. R.; VILLAS-BOAS, V.. Estudo de Adequações em um Aeroporto Regional para Alcançar a Eficiência Energética de Forma Renovável. Scientia cum indústria, v.4, n.1, p.21-31, 2016. DOI: http://doi.org/10.18226/23185279.v4iss1p21

EPE. Empreendimentos Fotovoltaicos: Instruções para Solicitação de Cadastramento e Habilitação Técnica com vistas à participação nos Leilões de Energia Elétrica. Rio de Janeiro: EPE, 2014.

EPE. Nota Técnica DEA19/14: Inserção da Geração Fotovoltaiva Distribuída no Brasil: Condicionantes e Impactos. Série Recursos Energéticos. Rio de Janeiro: EPE, 2014.

FLEURY, L. C.; ALMEIDA, J.. A construção da Usina Hidrelétrica de Belo Monte: conflito ambiental e o dilema do desenvolvimento. Ambient. Soc., p.141-156, 2013. DOI: https://doi.org/10.1590/S1414-753X2013000400009
GEHRING, A.; LOPES, L.; DALMOLIN, R.. Sistemas

fotovoltaicos conectados à rede: acompanhamento dos índices de mérito no escritório verde da UTFPR e análise da viabilidade econômica de implantação em residências. Monografia (Bacharelado) - Universidade Tecnológica Federal do Paraná, Curitiba, 2015.

LIU, Z.. China's Carbon Emissions Report 2015. Cambridge: Harvard Kennedy School, 2015.

LOPES, M. C.; TAQUES, F. H.. O Desafio da Energia Sustentável. Revista Cadernos de Economia, Chapecó, v.20, n.36, p.71-96, 2016.

MEYER, Y. A.; AVILA, L. F.; ORLANDINI, M. F.; NEVES, J. B.. Trabalhando a Física Moderna em um projeto de Iniciação Científica Júnior: A experimentação da medida da constante de Planck no Ensino Médio. REAe - Revista de Estudos Aplicados em Educação, v.4, n.7, 2019. DOI: https://doi.org/10.13037/rea-e.vol4n7.5776

RABUSKE, R.; FRIEDRICH, L. R.; FONTOURA, F. B. B.. Análise da viabilidade para implantação de energia fotovoltaica com utilização para sombreamento de estacionamento. Estudos do CEPE, p.36-48, 2018.

SILVA, F. R.; SILVA, O. R.; LIMA, F. L.; BASTOS, W. F.. Difusão da Inovação Tecnólogico: Um Estudo Sobre a Difusão da Energia Elétrica Fotovoltaica no Brasil. Revista Tecnologia, v.40, n.2, 2019. DOI: http://doi.org/10.5020/23180730.2019.9810

SILVA, R. G.; CARMO, M. J.. Energia Solar Fotovoltaica: uma proposta para melhoria da gestão energética. Inter Science Place, v.12, n.2, 2017.

SILVA, R. M.. Energia solar no Brasil: dos incentivos aos desafios. Brasília: Núcleo de Estudos e Pesquisas CONLEG, 2015.

SOUZA, A. C. D.. Análise dos impactos da geração distribuída por fonte solar fotovoltaica na qualidade da energia elétrica. Dissertação (Mestrado em Engenharia Elétrica) - Universidade Federal de Uberlândia, Uberlândia, 2016.

SOUZA, L. P. D.. Análise de viabilidade econômicofinanceira de uma microcervejaria artesanal na cidade de Porto Alegre. Monografia (Bacharelado em Administração) Universidade Federal do Rio Grande do Sul, Porto Alegre, 2017.

TOLLER, B. B.. Impacto técnico e econômico do uso de microturbinas para geração de energia elétrica em aterros sanitários sobre os sistemas de distribuição. Dissertação (Mestrado) - Universidade Federal de Santa Maria, Santa Maria, 2015. 
VIER, L. C.; SILVA, J. M.; BUENO, B. G.; SANTOS, R.;

RODRIGUES, M. F.. Estudo de viabilidade para utilização de placas fotovoltaicas em habitações populares. Revista GEDECON-Gestão e Desenvolvimento em Contexto, v.5, n.1, p.49-52, 2017. DOI: http://dx.doi.org/10.33053/gedecon.v5i1.5555

ZULPO, A. P.; CARVALHO, T. B.. Análise econômica de dois sistemas de produção de leite no meio oeste catarinense. Revista Agropecuária Catarinense, v.33, n.2, p.37-41, 2020.

A CBPC - Companhia Brasileira de Produção Científica (CNPJ: 11.221.422/0001-03) detém os direitos materiais desta publicação. Os direitos referem-se à publicação do trabalho em qualquer parte do mundo, incluindo os direitos às renovações, expansões e disseminações da contribuição, bem como outros direitos subsidiários. Todos os trabalhos publicados eletronicamente poderão posteriormente ser publicados em coletâneas impressas sob coordenação da Sustenere Publishing, da Companhia Brasileira de Produção Científica e seus parceiros autorizados. Os (as) autores (as) preservam os direitos autorais, mas não têm permissão para a publicação da contribuição em outro meio, impresso ou digital, em português ou em tradução. 